(C) 2022, The Authors. Published by Elsevier Inc. and Fass Inc. on behalf of the American Dairy Science Association ${ }^{\circledR}$. This is an open access article under the CC BY license (http://creativecommons.org/licenses/by/4.0/).

\title{
Reduced liner-open phase and vacuum instead of prestimulation increase parlor efficiency in dairy cows
}

Marion Tuor, Benjamin Jenni, Olga Wellnitz, (1) and Rupert M. Bruckmaier* (D)

Veterinary Physiology, Vetsuisse Faculty, University of Bern, 3001 Bern, Switzerland

\begin{abstract}
Adequate prestimulation is considered a requirement for a fast, gentle, and complete udder emptying at machine milking. Reduced vacuum or reduced liner-open phase of pulsation (or both) may replace prestimulation and consequently reduce work load of the milker and increase parlor efficiency. In the present study we compared 2 milking routines (MR) with manual prestimulation (LPrep $=$ long preparation: $15 \mathrm{~s}$ of forestripping, teat cleaning, and stimulation; SPrep $=$ short preparation: $5 \mathrm{~s}$ of teat cleaning) followed by 1-min latency period and milking at standard vacuum and pulsation settings (claw vacuum $44 \mathrm{kPa}$, pulsation rate 60 cycles $/ \mathrm{min}$, pulsation ratio $65 / 35$ ) with $2 \mathrm{MR}$ consisting of $5 \mathrm{~s}$ of teat cleaning, immediate cluster attachment and milking at reduced vacuum with or without shortened liner-open phase of pulsation until milk flow exceeded $400 \mathrm{~g} / \mathrm{min}(\mathrm{RP}=$ reduced pulsation: pulsation ratio $30 / 70$, pulsation rate 50 cycles/ min, claw vacuum $44 \mathrm{kPa}$; $\mathrm{RPV}=$ reduced pulsation and vacuum: pulsation ratio $30 / 70$, pulsation rate 50 cycles $/ \mathrm{min}$, claw vacuum $34 \mathrm{kPa}$ ). Cluster detachment was performed at $400 \mathrm{~g} / \mathrm{min}$ in all MR. Ten Holstein dairy cows were milked twice daily at 14 -h and $10-\mathrm{h}$ milking intervals. Milk flow and electrical conductivity (EC) were recorded throughout milking. During the first 2 min of each milking ultrasound cross-section images of the gland cistern of one front quarter were recorded, and 5 min after the end of milking teat tissue thickness of both front teats was measured by using a cutimeter. Most milking characteristics such as total milk yield, average milk flow, and machine-on time reached higher values at 14 -h than 10 -h milking intervals, but did not differ among MR. However, the occupancy time (time from the first touch of the udder until cluster detachment) was considerably shorter in RP and RPV compared with LPrep and SPrep. Ultrasound cross section areas of the gland cistern were
\end{abstract}

Received August 17, 2021.

Accepted October 20, 2021.

*Corresponding author: rupert.bruckmaier@vetsuisse.unibe.ch larger in LPrep than in RP and RPV indicating that milk ejection already occurred at cluster attachment in LPrep. This assumption is also supported by the lower EC at cluster attachment in LPrep than in RP and RPV, which was caused by the presence of alveolar milk in the gland cistern after milk ejection. The MR RP and RPV increase parlor efficiency and are worksaving alternatives to MR, which include an adequate prestimulation (LPrep). However, shortening prestimulation to a 5-s teat cleaning followed by a latency period and milking at regular vacuum and pulsation is not adequate to save occupancy time. Because milking was performed at a relatively low vacuum $(44 \mathrm{kPa})$ and at a detachment level of $400 \mathrm{~g} / \mathrm{min}$, teat tissue thickness did not differ among MR, and the vacuum reduction in RPV did not cause an additional advantage for teat condition compared with RP.

Key words: prestimulation, ultrasound, teat condition, reduced vacuum, shortened b-phase

\section{INTRODUCTION}

Adequate udder preparation is indispensable to empty the udder quickly and completely with a minimum mechanical impact on the teat tissue. On the other hand, a prestimulation without simultaneous removal of milk, both manual or mechanical, is labor intensive and time consuming. Therefore, manual prestimulation is often renounced in practical farms. Before milk ejection, only up to $20 \%$ of the milk in the udder, the cisternal milk, is immediately available for milk removal. The major part of the milk, the alveolar milk, is only available after myoepithelial contraction (Knight et al., 1994; Pfeilsticker et al., 1996), which is induced by the release of oxytocin in response to tactile teat stimulation (Bruckmaier et al., 1994). The quantity of cisternal milk is larger in early than late lactation and larger at long than short intervals after previous milking (i.e., the cisternal milk fraction increases with increasing degree of udder filling; Bruckmaier and Hilger, 2001). In addition, the lag time of milk ejection after the start of tactile teat stimulation is short at less than $1 \mathrm{~min}$ in well-filled udders, and may last for several minutes at 
a low degree of udder filling (Bruckmaier and Hilger, 2001; Erskine et al., 2019). The smaller the amount of immediately available cisternal milk before milking, the more important is a sufficient prestimulation for a timely induction of milk ejection to allow a high intracisternal pressure at cluster attachment and a milking process without interruption of milk flow (Bruckmaier and Blum, 1996). A transient cessation of milk flow after the removal of cisternal milk and before the occurrence of alveolar milk ejection (bimodality of milk flow) at a regular full vacuum level must be avoided because it increases the mechanical load on the teat tissue and can lead to preterm climbing of the teat cup. It may also cause a reverse pressure gradient in teat cistern that increases the risk of a cross contamination of quarters (Rasmussen et al., 1994). A continuous prestimulation is not necessary. A short prestimulation of $15 \mathrm{~s}$ followed by a latency period of up to 1 min has been shown to be similarly efficient as a continuous prestimulation (Kaskous and Bruckmaier, 2011; Vetter et al., 2014). A longer latency period after prestimulation is not recommended because the oxytocin blood concentrations decrease very fast in the absence of a tactile stimulus, which causes a partial decline of intracisternal pressure within 1 to 2 min (Mayer et al., 1984; Bruckmaier et al., 2001). However, it was until now not studied if a short teat cleaning for $5 \mathrm{~s}$ followed by a 1-min latency period can also be sufficient as an adequate udder preparation.

Tactile prestimulation can be replaced by immediate cluster attachment after a short teat cleaning but at a reduced vacuum level and shortened liner-open phase of pulsation until milk ejection occurs. Technical solutions are available that the milking unit detects the occurrence of milk ejection based on the recorded milk flow. The stimulatory effect of this system with respect to the induction of oxytocin release and milk ejection has been demonstrated (Neuheuser et al., 2018). However, information about the efficiency of such milking systems compared with short prestimulation followed by a latency period is missing. Therefore, the goal of this study was to compare the efficiency of milking routines with short teat cleaning or regular prestimulation $(5 \mathrm{~s}$ vs. $15 \mathrm{~s}$, followed by a 1-min latency period) with milking routines that include a 5 -s teat cleaning followed by immediate cluster attachment either with reduced vacuum or reduced vacuum and shortened b-phase of pulsation until the milk flow surmounted $400 \mathrm{~g} / \mathrm{min}$. To record the availability of milk for the milking machine and to detect potentially delayed milk ejection, we have used the number of bimodalities of milk flow curves but also continuous recording of electrical conductivity (EC) and continuous ultrasound imaging of the gland cistern of one quarter during the first 2 min of milking.

\section{MATERIALS AND METHODS}

The experiments of the present study followed the requirement of Swiss animal protection and welfare law and were approved by the Veterinary Office of the Canton of Fribourg (authorization no. 2020_40_FR).

\section{Animals and Housing}

Ten Holstein dairy cows from the Swiss Federal Research Station Agroscope Posieux were used for the trial. At the beginning of the trial the cows were in early lactation (72-119 DIM) of their second to fifth lactation [second $(\mathrm{n}=3)$, third $(\mathrm{n}=2)$, fourth $(\mathrm{n}=2)$, and fifth $(\mathrm{n}=3)]$. The 305-d milk production in their previous lactation ranged between 6,519 and $10,250 \mathrm{~kg}$ $(8,316 \pm 408 \mathrm{~kg})$. A general health check was performed before the trial started. None of the cows showed signs of a clinical mastitis or other diseases. The trial was conducted in 2 groups ( 5 cows each) and the cows were kept in a tiestall barn for the experimental milkings. The cows were fed TMR consisting of corn silage, grass silage, and aftermath, as well as minerals and concentrate according to their individual production levels after each milking.

\section{Milking Equipment and Milking Routines}

During the trial, cows were milked twice daily by the same person at 0600 and $1600 \mathrm{~h}$ [i.e., at milking intervals (MI) of 14 and $10 \mathrm{~h}$, respectively]. The milker wore gloves and forestripping was performed into a cup (2-3 squirts per teat). Disposable disinfectant cloths were used for teat cleaning. Milking was performed with a bucket milker connected to a milk-flow-controlled vacuum- and pulsation- adjustable milking unit (MU BLUE, DeLaval). The milking cluster consisted of a top flow claw (Harmony, DeLaval) and teat cups with round rubber liners (product number 99900901, DeLaval). The claw vacuum in the absence of milk flow was set at $44 \mathrm{kPa}$. The claw vacuum during the plateau phase of milk flow ranged between 31 and $37 \mathrm{kPa}$ depending on the milk flow level of the individual cow. Four different milking routines (MR) with different duration of teat preparation and different vacuum and pulsation settings at the start of milking were conducted. Each MR was applied at 2 morning milkings and 2 evening milkings in each cow in a randomized crossover design. An overview of the chronological sequence of all MR and the used recordings is illustrated in Figure 1. The details of the settings of the milking units in all MR are shown in Table 1. The long preparation (LPrep) MR consisted of a 15-s manual forestripping, teat cleaning, and stimulation followed by a 1-min latency period be- 


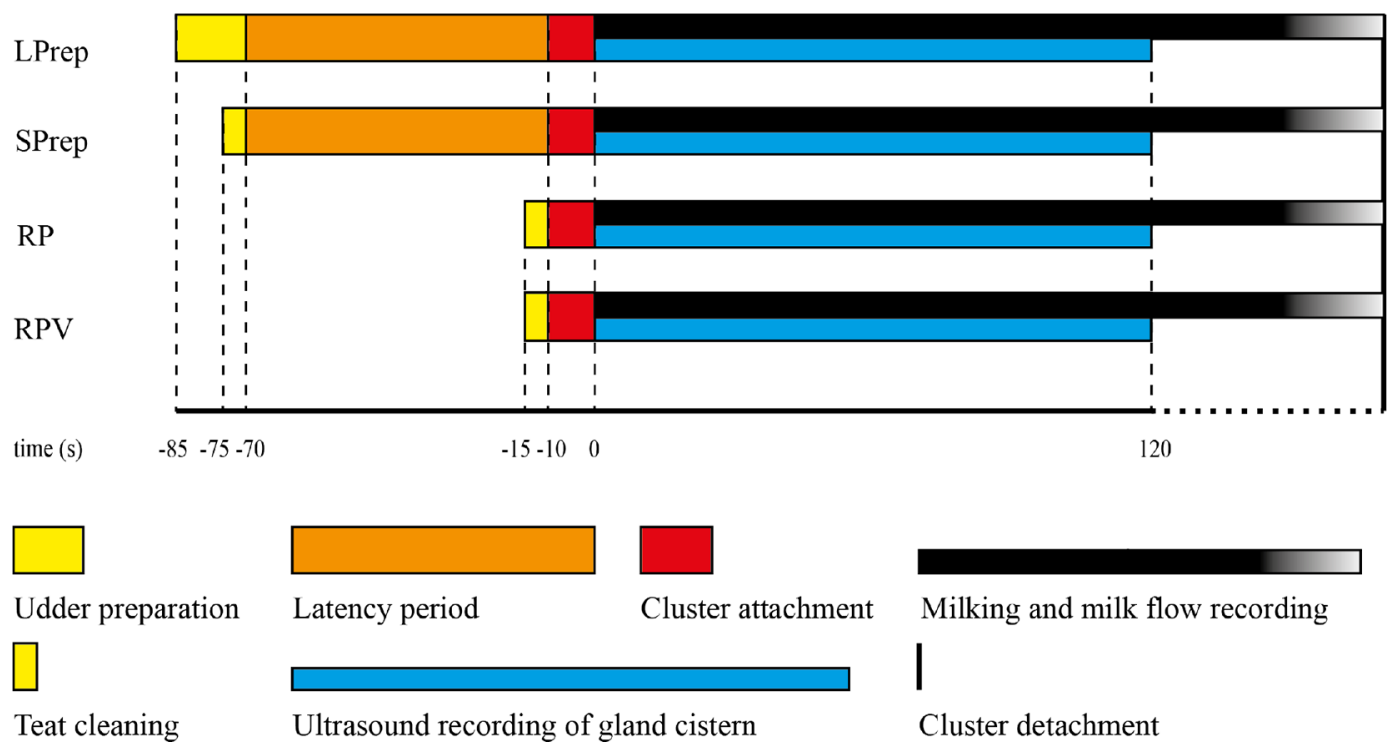

Figure 1. Sequence of events in the 4 different milking routines and applied methods. Measurements of the teat thickness using a cutimeter were conducted $5 \mathrm{~min}$ after cluster detachment (not shown in this figure). LPrep = long preparation; SPrep = short preparation; RP = reduced pulsation; RPV = reduced pulsation and vacuum.

fore cluster attachment at full claw vacuum and normal pulsation throughout milking (claw vacuum $44 \mathrm{kPa}$, pulsation rate 60 cycles/min; pulsation ratio $65 / 35)$. The short preparation (SPrep) MR consisted of a 5-s teat cleaning followed by a 1-min latency period before cluster attachment at full claw vacuum and normal pulsation throughout milking like MR LPrep. The reduced pulsation (RP) MR consisted of a 5-s teat cleaning and immediate cluster attachment at a $44 \mathrm{kPa}$ vacuum, but reduced pulsation ratio $(30 / 70)$ and pulsation rate (50 cycles/min) until the milking unit switched to the normal pulsation at a milk flow of $400 \mathrm{~g} / \mathrm{min}$. In the reduced pulsation and vacuum (RPV) MR, the cluster was attached immediately after $5 \mathrm{~s}$ of teat cleaning.
Milking started at a RP ratio (30/70) and pulsation rate $(50$ cycles $/ \mathrm{min})$, and in addition at a reduced claw vacuum $(34 \mathrm{kPa})$ until the milking unit switched to normal vacuum and pulsation settings as soon as a milk flow of $400 \mathrm{~g} / \mathrm{min}$ was reached. Cluster detachment was performed manually at $400 \mathrm{~g} / \mathrm{min}$ (without delay time) in all MR.

\section{Milk Flow Recording and Milking Characteristics}

During all experimental milkings milk flow and EC of the milk were recorded by a portable electronic recording unit (LactoCorder, WMB AG). We analyzed the following milking characteristics as calculated by the

Table 1. Specification of different events and milking machine settings during the milking process with the 4 different milking routines

\begin{tabular}{|c|c|c|c|c|}
\hline Item & \multicolumn{4}{|c|}{ Milking routine $^{1}$} \\
\hline Preparation & $\begin{array}{l}\text { 15-s manual forestripping, teat } \\
\text { cleaning, and stimulation }\end{array}$ & 5-s teat cleaning & 5-s teat cleaning & 5 -s teat cleaning \\
\hline \multirow{2}{*}{\multicolumn{5}{|c|}{ Settings until milk flow of $400 \mathrm{~g} / \mathrm{min}$}} \\
\hline & & & & \\
\hline Claw vacuum (kPa) & 44 & 44 & 44 & 34 \\
\hline \multicolumn{5}{|c|}{ Settings at a milk flow of $400 \mathrm{~g} / \mathrm{min}$} \\
\hline Claw vacuum $(\mathrm{kPa})$ & 44 & 44 & 44 & 44 \\
\hline Pulsation ratio & $65 / 35$ & $65 / 35$ & $65 / 35$ & $65 / 35$ \\
\hline Pulsation rate (cycles/min) & 60 & 60 & 60 & 60 \\
\hline Cluster detachment (g/min) & 400 & 400 & 400 & 400 \\
\hline
\end{tabular}

${ }^{1}$ LPrep = long preparation; SPrep = short preparation; $\mathrm{RP}=$ reduced pulsation; $\mathrm{RPV}=$ reduced pulsation and vacuum. 
LactoPro software (version 6.0.60, WMB AG): total milk yield (TMY), machine-on time (MOT), average milk flow (AMF; calculated by TMY/MOT), duration of plateau ( $\mathbf{d P}$; time period between threshold slopes of $<0.8$ and $>0.8 \mathrm{~kg} / \mathrm{min}^{2}$ milk flow), duration of decline (dD; time period after plateau phase until cluster detachment), peak flow rate (PFR; maximum milk flow maintained for at least $22.4 \mathrm{~s}$ ), the EC at cluster attachment (maximum EC value from milk flow of $0.20 \mathrm{~kg} / \mathrm{min}$ until the end of the start-peak), and the decline of EC after cluster attachment (EC at cluster attachment minus the value at the point of reaching $\mathrm{EC}$ values with a maximum difference of $0.04 \mathrm{mS} / \mathrm{cm}$ ). By summation of MOT, time for forestripping, teat cleaning and stimulation, and latency period, we defined the occupancy time (OCT) as the time from the first touch of the udder until cluster detachment. From each bimodal milk curve, the highest milk flow during the first peak and the nadir between the 2 peaks, and the magnitude of the decline from the first peak to the nadir was determined. A milk flow curve was defined as bimodal if the milk flow declined at least by $100 \mathrm{~g} /$ min during the incline phase for at least $2.8 \mathrm{~s}$. Based on the nadir between the 2 peaks, the bimodalities of milk flow curves were classified as severe (nadir of milk flow $\leq 1 \mathrm{~kg} / \mathrm{min}$ ) or light (nadir of milk flow $>1 \mathrm{~kg}$ / $\min )$.

\section{Ultrasound Recordings of One Gland Cistern}

During each milking B-mode ultrasound cross sections of one front quarter gland cistern were continuously recorded with a portable ultrasound device (Draminski 4Vet; Draminski S.A.). A convex probe (2 to $8 \mathrm{MHz}$, radius $50 \mathrm{~mm}$, penetration depth $150 \mathrm{~mm}$ ) was placed at the udder directly above the teat base and parallel to the teat. A thick type of ultrasound gel (Lubricant Gel, Henry Schein) was used as a coupling medium. In a test attempt before the experiment, the more suitable front quarter of each cow concerning repeatability and image quality of the ultrasound record was chosen, the hair clipped, and the quarter was used throughout the trial. Hair clipping served also as a marker to identify the exact placement of the ultrasound probe on the udder. Ultrasound imaging was applied from cluster attachment until 2 min of milking. To analyze the ultrasound records, they were converted to image files ( 1 image per s) by a converter (Free Video to JPG Converter, version 5.0.101, Digital Wave Ltd.). A cutout, recognized by different markers of tissue, of the recorded gland cistern was measured using graphic editing software (Photoshop, version 22.3.0, Adobe). The measured pixels were converted into $\mathrm{cm}\left(1,681\right.$ pixel $\left.=1 \mathrm{~cm}^{2}\right)$. Measurements were performed every $10 \mathrm{~s}$. If the cisternal area changed between 2 images, additional measurements were added during the respective 10-s interval to determine the exact time of the shrinking or enlargement of the area (e.g., due to delayed milk ejection).

\section{Teat Condition Measurements}

At 5 min after cluster detachment the teat tissue thickness of the front teat was measured using a springloaded caliper (cutimeter, Hauptner und Herberholz) with a spring constant of $3.38 \mathrm{~N} / \mathrm{cm}$ (4 N at closed jaws) as previously described (Hamann and Mein, 1988; Odorcic et al., 2020; Stauffer et al., 2020). This timing was chosen based on previous experience that the teat is still thickening in the first few minutes after cluster detachment. One measurement was performed directly at the tip of the teat and a second measurement at the teat barrel $2 \mathrm{~cm}$ above the tip of the teat. After the teat measurements, all the teats were dipped with an iodine-based teat dip agent.

\section{Statistical Analysis}

The data are presented as arithmetic means and standard errors of the means. The SAS software was used (version 9.4, SAS Institute Inc.) for statistical analysis. Statistical testing was performed based on LSMEANS using the MIXED procedure of SAS. The model included the MR and MI as fixed effects and the cow as repeated and random factor. Differences of MR were localized by the Tukey-Kramer test and considered as significant if $P<0.05$. Differences at $0.05<P<0.10$ were considered as tendencies.

\section{RESULTS}

\section{Milking Characteristics}

Results of milking characteristics are presented in Table 2. The TMY ranged from 13.56 to $24.09 \mathrm{~kg}$ at 14-h MI and from 10.18 to $18.23 \mathrm{~kg}$ at 10-h MI. The TMY was higher $(P<0.05)$ at 14 -h MI than at $10-\mathrm{h}$ MI in all MR but did not differ among MR. The AMF was higher at 14-h than at 10-h MI in SPrep, RP, and RPV $(P<0.05)$. At 14 -h MI there were no differences among MR. At 10-h MI AMF was higher in LPrep than in RP and RPV $(P<0.05)$. The $\mathrm{dP}$ was longer at $14-\mathrm{h}$ MI than at $10-\mathrm{h}$ MI in all MR $(P<0.05)$. Among MR $\mathrm{dP}$ did not differ. The $\mathrm{dD}$ was longer at 14 -h MI than at $10-\mathrm{h}$ MI in LPrep, SPrep, and RPV $(P<0.05)$ and also tended to be longer in $\mathrm{RP}(P=0.053)$ at 14 -h MI than at 10-h MI. The $\mathrm{dD}$ did not differ among MR 
Table 2. Milking characteristics (means \pm SEM) with different milking routines (MR) and milking intervals (MI)

\begin{tabular}{|c|c|c|c|c|c|}
\hline Milking variable & $\begin{array}{l}\text { MI } \\
\text { (h) }\end{array}$ & \multicolumn{4}{|c|}{$\mathrm{MR}^{1}$} \\
\hline Total milk yield $(\mathrm{kg})$ & 14 & $18.56 \pm 0.51^{*}$ & $18.49 \pm 0.50^{*}$ & $18.60 \pm 0.58^{*}$ & $19.12 \pm 0.56^{*}$ \\
\hline \multirow{2}{*}{ Average milk flow $(\mathrm{kg} / \mathrm{min})$} & 14 & $2.93 \pm 0.18$ & $2.90 \pm 0.17^{*}$ & $2.83 \pm 0.16^{*}$ & $2.80 \pm 0.17^{*}$ \\
\hline & 10 & $2.82 \pm 0.17^{\mathrm{a}}$ & $2.69 \pm 0.13^{\mathrm{ab}}$ & $2.57 \pm 0.15^{\mathrm{b}}$ & $2.57 \pm 0.15^{\mathrm{b}}$ \\
\hline Duration of plateau (min) & 14 & $2.81 \pm 0.27^{*}$ & $2.42 \pm 0.21^{*}$ & $2.62 \pm 0.25^{*}$ & $2.55 \pm 0.18^{*}$ \\
\hline Peak flow rate $(\mathrm{kg} / \mathrm{min})$ & 10 & $4.11 \pm 0.20$ & $4.16 \pm 0.18$ & $4.08 \pm 0.22$ & $4.02 \pm 0.20$ \\
\hline \multirow[t]{2}{*}{ Duration of decline (min) } & 14 & $3.16 \pm 0.36^{*}$ & $3.16 \pm 0.36^{*}$ & $3.03 \pm 0.34 \dagger$ & $3.42 \pm 0.38^{*}$ \\
\hline & 10 & $2.51 \pm 0.30$ & $2.54 \pm 0.23$ & $2.60 \pm 0.25$ & $2.47 \pm 0.28$ \\
\hline \multirow[t]{2}{*}{ Machine-on time (min) } & 14 & $6.80 \pm 0.45^{*}$ & $6.78 \pm 0.40^{*}$ & $6.91 \pm 0.39^{*}$ & $7.23 \pm 0.42^{*}$ \\
\hline & 10 & $5.31 \pm 0.37$ & $5.54 \pm 0.26$ & $5.76 \pm 0.32$ & $5.73 \pm 0.31$ \\
\hline \multirow{2}{*}{ Occupancy time (min) } & 14 & $8.05 \pm 0.45^{\text {a* }}$ & $7.86 \pm 0.40^{\mathrm{a} *}$ & $6.99 \pm 0.39^{\mathrm{b} *}$ & $7.31 \pm 0.42^{\mathrm{b} *}$ \\
\hline & 10 & $6.56 \pm 0.37^{\mathrm{a}}$ & $6.62 \pm 0.26^{\mathrm{a}}$ & $5.85 \pm 0.32^{\mathrm{b}}$ & $5.81 \pm 0.31^{\mathrm{b}}$ \\
\hline
\end{tabular}

${ }^{\mathrm{a}-\mathrm{c}}$ Means with different superscripts differ significantly $(P<0.05)$ between MR within the same MI.

${ }^{1}$ LPrep $=$ long preparation; SPrep $=$ short preparation; $\mathrm{RP}=$ reduced pulsation; $\mathrm{RPV}=$ reduced pulsation and vacuum.

${ }^{2} \mathrm{EC}=$ electrical conductivity.

${ }^{*}$, Means differed significantly $\left({ }^{*} P<0.05\right)$ or tended to differ $(\dagger P=0.05-0.1)$ between 14 -h and 10 -h MI within the same MR.

at both 14-h and 10-h MI. The PFR did not differ between 14-h and 10-h MI and there were no differences among MR. The MOT ranged from 3.73 to $10.45 \mathrm{~min}$ at 14 -h MI and from 3.15 to 8.63 min at $10-\mathrm{h}$ MI. The MOT was longer at 14 -h MI than at $10-\mathrm{h}$ MI $(P<$ $0.05)$ in all MR. The MOT did not differ among MR. The OCT ranged from 4.27 to $11.53 \mathrm{~min}$ at 14 -h MI and from 3.67 to $9.52 \mathrm{~min}$ at 10-h MI. It was longer at 14-h MI than at 10-h MI in all MR and was longer in LPrep and SPrep than in RP and RPV $(P<0.05)$ at both 14-h and 10-h MI.

The EC at cluster attachment was lower in LPrep than in RP and RPV $(P<0.05)$ at 14 -h MI. At 10 -h MI EC at cluster attachment was lower in LPrep than in $\operatorname{RP}(P<0.05)$ and tended to be lower in LPrep than in SPrep $(P=0.075)$ and RPV $(P=0.098)$. The decline of EC after cluster attachment was lower in LPrep than in $\mathrm{RP}$ and $\operatorname{RPV}(P<0.05)$ and lower in SPrep than in RPV $(P<0.05)$ at 14 -h MI. At 10 -h MI the decline was lower in LPrep than in SPrep, RP, and $\operatorname{RPV}(P<0.05)$.

\section{Bimodalities of Milk Flow}

Table 3 shows the frequencies of bimodalities of each MR at both MI. Bimodal milk flow was more often observed at $10-\mathrm{h}$ than at $14-\mathrm{h}$ MI in all MR. The highest number of bimodality was observed in RP. The lowest number of bimodality occurred in LPrep. In all MR, severe bimodalities occurred more often at 10 -h than at 14-h MI. The most severe bimodalities were observed in RP at 10-h MI. In LPrep and RPV severe bimodalities did not occur at 14-h MI, and at 10-h MI in LPrep only in $10 \%$ of milkings.

The EC at cluster attachment was higher in bimodal than in non-bimodal milk flow curves $(6.77 \pm 0.07 \mathrm{mS} /$ $\mathrm{cm}$ and $6.51 \pm 0.05 \mathrm{mS} / \mathrm{cm}$, respectively, $P<0.05)$. The decline of EC after cluster attachment was greater in bimodal than in non-bimodal milk flow curves $(0.64$ $\pm 0.05 \mathrm{mS} / \mathrm{cm}$ and $0.35 \pm 0.03 \mathrm{mS} / \mathrm{cm}$, respectively, $P<0.05)$. The area of gland cistern at cluster attachment was larger in non-bimodal than in bimodal milk flow curves $\left(17.45 \pm 1.05 \mathrm{~cm}^{2}\right.$ and $13.64 \pm 1.12 \mathrm{~cm}^{2}$, respectively, $P<0.05)$.

\section{Ultrasound and Teat Condition}

At cluster attachment, the area of the gland cistern on the ultrasound image was larger at 14-h MI than at 10-h MI in all MR $(P<0.05$, Table 4$)$. At 14 -h MI the area was larger in LPrep than in RP and in LPrep it tended to be larger than in RPV $(P=0.076)$. At 10 -h MI the area was larger in LPrep than in RP and RPV, and it was larger in SPrep than in RP. In SPrep the area tended to be larger than in $\operatorname{RPV}(P=0.077)$. At 2 min of milking the area of the gland cistern did not differ among MI and there were no differences among MR. Teat condition based on cutimeter measurements did not significantly differ between 14 -h and 10-h MI or among MR (Table 5). 
Table 3. Frequency (\%) of observed bimodalities ( $\geq 100 \mathrm{~g} / \mathrm{min}$ decline of milk flow during incline phase) with different milking routines $(\mathrm{MR})$ and milking intervals $(\mathrm{MI})^{1}$

\begin{tabular}{llccc}
\hline \multirow{2}{*}{ MR $^{2}$} & $\begin{array}{l}\text { MI } \\
(\mathrm{h})\end{array}$ & Total bimodalities & $\begin{array}{c}\text { Severe } \\
(\text { nadir } \leq 1 \mathrm{~kg} / \mathrm{min})\end{array}$ & $\begin{array}{c}\text { Light } \\
\text { (nadir }>1 \mathrm{~kg} / \mathrm{min})\end{array}$ \\
\hline LPrep & 14 & 5 & 0 & 5 \\
& 10 & 15 & 10 & 5 \\
SPrep & 14 & 30 & 10 & 20 \\
& 10 & 45 & 30 & 15 \\
$\mathrm{RP}$ & 14 & 60 & 10 & 50 \\
$\mathrm{RPV}$ & 10 & 85 & 60 & 35 \\
& 14 & 35 & 0 & 15
\end{tabular}

${ }^{1}$ The total number of bimodalities of each MR and MI has been divided depending on the nadir of the milk flow after the first peak in severe (nadir of milk flow $\leq 1 \mathrm{~kg} / \mathrm{min}$ ) and light (nadir of milk flow $>1 \mathrm{~kg} / \mathrm{min}$ ) bimodalities.

${ }^{2} \mathrm{LPrep}=$ long preparation; SPrep $=$ short preparation; $\mathrm{RP}=$ reduced pulsation; $\mathrm{RPV}=$ reduced pulsation and vacuum.

\section{DISCUSSION}

In the present study, we compared the efficiency of 4 different MR either consisting of a regular or very short teat preparation combined with a 1-min latency period and milking at standard vacuum and pulsation settings (LPrep and SPrep, respectively) or immediate attachment and milking with reduced liner-open phase either alone or combined with reduced vacuum during low milk flow (RP and RPV, respectively). The stimulatory effect of reduced vacuum and shortened liner-open phase during low milk flow to induce oxytocin release and hence milk ejection has been previously demonstrated (Neuheuser et al., 2018).

The TMY was higher at 14-h than 10-h MI but did not differ between the $4 \mathrm{MR}$. In accordance with previous studies, udder emptying was similarly complete, independent of the type and duration of prestimulation and vacuum load at the start of milking (Bruckmaier and Blum, 1996; Weiss and Bruckmaier, 2005; Neuheuser et al., 2018) and independent of the degree of udder filling caused by short and long MI (Kaskous and Bruckmaier, 2011).
The AMF was higher at 14-h than 10-h MI except for LPrep where a significant effect of MI on AMF was not observed. Because PFR did not differ among MI or $\mathrm{MR}$, the higher AMF at 14-h than 10-h MI was mainly caused by the higher TMY as a reason for the longer $\mathrm{dP}$ at 14-h than 10-h MI in all MR. It has been previously demonstrated that the degree of udder filling at different stages of lactation mainly affects the $\mathrm{dP}$ as a reason for different AMF (Mayer et al., 1991). The ultrasound records of the gland cistern clearly demonstrated a larger cisternal area at cluster attachment at 14-h than at 10-h MI in all MR, indicating a larger quantity of cisternal milk. This could also be an additional reason for the higher AMF at 14-h than 10-h MI. The correlation between quantity of cisternal milk and the cisternal area on ultrasound cross sections as well as the increase of the cisternal area at increasing MI has previously been demonstrated (Ayadi et al., 2003; Caja et al., 2004). Furthermore, milk ejection occurs faster in response to prestimulation and oxytocin release at a higher degree of udder filling (Bruckmaier et al., 1994; Bruckmaier and Hilger, 2001), which was likely also responsible for the lower frequency of bimodalities at

Table 4. Gland cistern area (means \pm SEM) of one front quarter measured by ultrasound at cluster attachment and at 2 min of milking with different milking routines (MR) and milking intervals (MI)

\begin{tabular}{|c|c|c|c|c|c|}
\hline \multirow[b]{2}{*}{ Size of the gland cistern area } & \multirow{2}{*}{$\begin{array}{l}\text { MI } \\
(\mathrm{h})\end{array}$} & \multicolumn{4}{|c|}{$\mathrm{MR}^{1}$} \\
\hline & & LPrep & SPrep & $\mathrm{RP}$ & $\mathrm{RPV}$ \\
\hline \multirow{2}{*}{ At cluster attachment $\left(\mathrm{cm}^{2}\right)$} & 14 & $19.6 \pm 2.6^{\text {a* }}$ & $19.3 \pm 2.2^{\mathrm{ab} *}$ & $16.5 \pm 1.9^{\mathrm{b} *}$ & $16.8 \pm 2.2^{\mathrm{ab} *}$ \\
\hline & 10 & $16.1 \pm 2.4^{\mathrm{a}}$ & $15.1 \pm 2.4^{\mathrm{ab}}$ & $11.3 \pm 1.7^{\mathrm{c}}$ & $12.8 \pm 1.9^{\mathrm{bc}}$ \\
\hline \multirow{2}{*}{ At 2 min of milking $\left(\mathrm{cm}^{2}\right)$} & 14 & $22.5 \pm 2.7$ & $22.2 \pm 2.8$ & $22.1 \pm 2.1$ & $21.4 \pm 2.2$ \\
\hline & 10 & $20.5 \pm 2.4$ & $19.6 \pm 2.4$ & $20.2 \pm 2.0$ & $19.8 \pm 2.0$ \\
\hline
\end{tabular}

${ }^{\mathrm{a}-\mathrm{c}}$ Means with different superscripts differ significantly $(P<0.05)$ between MR within the same MI.

${ }^{1} \mathrm{LPrep}=$ long preparation; $\mathrm{SPrep}=$ short preparation; $\mathrm{RP}=$ reduced pulsation; $\mathrm{RPV}=$ reduced pulsation and vacuum.

*Means differ significantly $(P<0.05)$ between the 14 -h and 10 -h MI within the same MR. 
Table 5. Teat thickness (means \pm SEM) of the front teats at 5 min after cluster detachment with different milking routines (MR) and milking intervals (MI) measured by cutimeter

\begin{tabular}{|c|c|c|c|c|c|}
\hline \multirow[b]{2}{*}{ Variable } & \multirow{2}{*}{$\begin{array}{l}\text { MI } \\
(\mathrm{h})\end{array}$} & \multicolumn{4}{|c|}{$\mathrm{MR}^{1}$} \\
\hline & & LPrep & SPrep & $\mathrm{RP}$ & $\mathrm{RPV}$ \\
\hline \multirow{2}{*}{ Left front teat tip (mm) } & 14 & $10.02 \pm 0.23$ & $10.07 \pm 0.27$ & $9.83 \pm 0.25$ & $9.84 \pm 0.21$ \\
\hline & 10 & $9.94 \pm 0.21$ & $10.30 \pm 0.33$ & $9.93 \pm 0.25$ & $9.87 \pm 0.16$ \\
\hline \multirow{2}{*}{ Left front teat barrel $(\mathrm{mm})$} & 14 & $10.38 \pm 0.28$ & $10.27 \pm 0.29$ & $10.15 \pm 0.40$ & $9.94 \pm 0.34$ \\
\hline & 10 & $10.32 \pm 0.27$ & $10.55 \pm 0.34$ & $9.99 \pm 0.40$ & $10.10 \pm 0.28$ \\
\hline \multirow[t]{2}{*}{ Right front teat tip (mm) } & 14 & $10.00 \pm 0.17$ & $10.13 \pm 0.22$ & $10.25 \pm 0.20$ & $10.17 \pm 0.17$ \\
\hline & 10 & $10.09 \pm 0.16$ & $10.43 \pm 0.30$ & $10.45 \pm 0.21$ & $10.25 \pm 0.13$ \\
\hline \multirow[t]{2}{*}{ Right front teat barrel (mm) } & 14 & $10.26 \pm 0.29$ & $10.37 \pm 0.33$ & $10.47 \pm 0.40$ & $10.12 \pm 0.35$ \\
\hline & 10 & $10.22 \pm 0.33$ & $10.26 \pm 0.32$ & $10.17 \pm 0.38$ & $10.20 \pm 0.34$ \\
\hline
\end{tabular}

${ }^{1}$ LPrep $=$ long preparation; SPrep $=$ short preparation; $\mathrm{RP}=$ reduced pulsation; $\mathrm{RPV}=$ reduced pulsation and vacuum.

14-h than 10-h MI in the present study. Previous studies have also demonstrated a larger cisternal milk fraction at a higher degree of udder filling as a consequence of both long MI and early lactational stage (Knight et al., 1994; Pfeilsticker et al., 1996; Bruckmaier and Hilger, 2001).

The AMF did not differ among MR at 14-h MI (i.e., at a high degree of udder filling), whereas differences of AMF among MR were observed at the lower udder filling at the 10-h MI. Expectedly, LPrep was the MR that caused an early milk ejection and hence immediate availability of alveolar milk after cluster attachment, which was not the case in RP and RPV. This is also reflected by the higher number of observed bimodalities in RP and RPV than in LPrep. The AMF in SPrep at 10-h MI did not differ from any other MR. Numerically, the mean AMF in SPrep was lower than in LPrep, and higher than in RP and RPV. This may indicate that in some SPrep milkings the 5 -s prestimulation has caused a partial milk ejection but not in all milkings. In a previous study, the cannulation of one teat caused, in only some cases, a slight and transient increase of plasma oxytocin concentration and hence a partial milk ejection (Mayer et al., 1991). In contrast, a reliable stimulatory effect on the release of oxytocin and milk ejection was previously demonstrated by a 15 -s manual prestimulation followed by a latency period of up to 1 min before cluster attachment such as in LPrep (Kaskous and Bruckmaier, 2011; Vetter et al., 2014). In both RP and RPV the cluster was attached immediately after the 5 -s teat cleaning and hence before the occurrence of milk ejection, which has been shown to take at least $30 \mathrm{~s}$ after the first tactile contact with the teats (Weiss and Bruckmaier, 2005). Because of the small amount of milk in the cistern at attachment in $\mathrm{RP}$ and RPV as demonstrated by the smaller cisternal area on ultrasound, bimodalities of milk flow were more frequently observed in RP and RPV than in LPrep. This observation was also confirmed by the generally smaller ultrasound gland cistern area at cluster attachment in bimodal than non-bimodal milk flow milkings. In SPrep the cisternal area on ultrasound at cluster attachment was almost as large as in LPrep, which confirms the assumed partial milk ejection even due to the short 5 -s teat cleaning followed by the 1-min latency period. Because of the short half-life of oxytocin (Belo and Bruckmaier, 2010), a small increase of oxytocin as induced by a 5 -s teat cleaning returns immediately toward baseline and milk ejection remains incomplete as indicated at least in a portion of the SPrep milkings. An additional indicator of milk ejection is the characteristic decline of EC during milk ejection caused by high EC in cisternal milk and lower levels in alveolar milk fractions (Bruckmaier et al., 2004). Therefore, EC at cluster attachment was higher in bimodal than non-bimodal milk flow curves and the decline of EC after cluster attachment was greater in bimodal than in non-bimodal milk flow curves also in the present study.

The MOT and dP did not differ among MR but were longer at 14-h than 10-h MI, which is in accordance with the higher TMY at the longer MI. Obviously, the higher AMF at 14-h than 10-h MI could only partially compensate for the difference of TMY, thus leading to longer MOT. This may be at least in part due to the higher number of total bimodalities and particularly severe bimodalities during milkings at $10-\mathrm{h}$ than $14-\mathrm{h}$ MI in all MR. This assumption is supported by the fact that the cisternal size at cluster attachment was smaller at 10-h than 14-h MI thus causing a faster emptying of the cisternal compartment and hence interruption of milk flow before the alveolar milk ejection takes place (Bruckmaier and Hilger, 2001). The occurrence of bimodal milk flow requires the presence of cisternal milk, which in turn depends of a certain degree of udder filling (Knight et al., 1994; Bruckmaier and Hilger, 2001). The relatively early stage of lactation of all experimental cows and the minimum MI of $10 \mathrm{~h}$ made sure that all udder quarters had a portion of cisternal milk, which 
is also confirmed by the visibility of cisternal cavities by ultrasound before milk ejection (RP and RPV) at both studied MI. The cluster attachment before the occurrence of milk ejection was also demonstrated by the smaller ultrasound cisternal size and hence higher frequency of bimodalities in RP and RPV compared with LPrep. Again, SPrep showed numerically an intermediate mean value of the mean cisternal area, smaller than in LPrep and larger than in RPV and RP (again not significantly different from most of the other MR). This strengthens the supposition that a partial milk ejection occurred in a portion but not all milkings in SPrep. This assumption is also supported by a numerically intermediate mean value of EC in SPrep at cluster attachment, higher than in LPrep and lower than in $\mathrm{RPV}$ and RP. To optimize gentle milk removal in RP and RPV, further technical developments should consider to include a delay time before the milking machine settings switch to the regular pulsation and full vacuum after the low milk flow limit is reached at the start of milking in RP and RPV. Such a delay time could be adjusted to the expected time from cluster attachment until milk ejection at different lactational stages and MI. Thus, a too fast milking before the occurrence of milk ejection and hence bimodal milk flow curves could likely be prevented.

The smaller ultrasound cisternal areas in RP and RPV compared with LPrep as well as in 10-h than 14-h MI at cluster attachment indicate the different quantities of milk present in the cistern. At 2 min of milking cisternal areas were considerably larger in all MR and no longer differed among MR and MI. It has previously been demonstrated that the increase of intracisternal pressure caused by milk ejection is higher at 10-h than 14-h MI at least during the first months of lactation, thus balancing the lower amount of cisternal milk by milk ejection as long as sufficient alveolar milk is available (Mayer et al., 1991).

The MOT represents the time needed for a milking process only partially because the duration of udder preparation and any latency period before cluster attachment are not included. Therefore, for an adequate calculation of milking time the activities before cluster attachment need to be considered, which is defined as OCT. As a result of the longer MOT at 14-h than 10-h $\mathrm{MI}$ in all MR, OCT was longer for 14-h than for 10-h MI in all MR as well. Expectedly OCT was shorter in both RP and RPV compared with both LPrep and SPrep. Thus, the work efficiency of MR with immediate cluster attachment after only a short teat cleaning is advantageous compared with treatments with longer teat preparation and latency periods. The OCT did not differ between RP and RPV. However, earlier studies demonstrated that a vacuum reduction during periods of low milk flow at the start and end of milking has a positive effect on the postmilking teat condition if milking was performed at a vacuum such as $50 \mathrm{kPa}$ to increase the milking performance (Besier and Bruckmaier, 2016; Stauffer et al., 2020). In the present study the claw vacuum in the absence of milk flow was only $44 \mathrm{kPa}$, and the additional vacuum reduction during low milk flow was not effective for both milking performance and postmilking teat condition.

The postmilking teat condition measured as teat tissue thickness by cutimeter both at the teat tip and teat barrel did not differ among the studied MR. Likely because of the moderate milking vacuum level in the present study, as well as the similar cluster detachment at $400 \mathrm{~g} / \mathrm{min}$ in all $\mathrm{MR}$, none of the MR caused a particularly increased mechanical load on the teats. It has been previously shown that the main impact on the teat causing increased teat tissue thickness occurs toward the end of milking and overmilking (Isaksson and Lind, 1992; Rasmussen, 1993; Odorcic et al., 2020). This was not the case in any of the MR used.

\section{CONCLUSIONS}

Milking routines with reduced liner-open phase and additionally reduced vacuum during low milk flow are efficient alternatives, saving work time and increasing parlor efficiency compared with milking after an adequate prestimulation. In contrast, the present study demonstrated that shortening a tactile prestimulation to $5 \mathrm{~s}$ followed by milking at regular pulsation and vacuum settings is inadequate and has no time-saving effect on milking even if combined with a 1-min latency period before cluster attachment.

\section{ACKNOWLEDGMENTS}

This research was supported by DeLaval (Tumba, Sweden). The authors have not stated any conflicts of interest.

\section{REFERENCES}

Ayadi, M., G. Caja, X. Such, and C. H. Knight. 2003. Use of ultrasonography to estimate cistern size and milk storage at different milking intervals in the udder of dairy cows. J. Dairy Res. 70:1-7. https://doi.org/10.1017/S0022029902005873.

Belo, C. J., and R. M. Bruckmaier. 2010. Suitability of low-dosage oxytocin treatment to induce milk ejection in dairy cows. J. Dairy Sci. 93:63-69. https://doi.org/10.3168/jds.2009-2084.

Besier, J., and R. M. Bruckmaier. 2016. Vacuum levels and milk-flowdependent vacuum drops affect machine milking performance and teat condition in dairy cows. J. Dairy Sci. 99:3096-3102. https:// doi.org/10.3168/jds.2015-10340. 
Bruckmaier, R. M., and J. W. Blum. 1996. Simultaneous recording of oxytocin release, milk ejection and milk flow during milking of dairy cows with and without prestimulation. J. Dairy Res. 63:201208. https://doi.org/10.1017/S0022029900031708.

Bruckmaier, R. M., and M. Hilger. 2001. Milk ejection in dairy cows at different degrees of udder filling. J. Dairy Res. 68:369-376. https:/ /doi.org/10.1017/S0022029901005015.

Bruckmaier, R. M., J. Macuhova, and H. H. D. Meyer. 2001. Specific aspects of milk ejection in robotic milking: A review. Livest. Prod. Sci. 72:169-176. https://doi.org/10.1016/S0301-6226(01)00277-9.

Bruckmaier, R. M., D. Schams, and J. W. Blum. 1994. Continuously elevated concentrations of oxytocin during milking are necessary for complete milk removal in dairy cows. J. Dairy Res. 61:323-334. https://doi.org/10.1017/S0022029900030740.

Bruckmaier, R. M., D. Weiss, M. Wiedemann, S. Schmitz, and G. Wendl. 2004. Changes of physicochemical indicators during mastitis and the effects of milk ejection on their sensitivity. J. Dairy Res. 71:316-321. https://doi.org/10.1017/S0022029904000366.

Caja, G., M. Ayadi, and C. H. Knight. 2004. Changes in cisternal compartment based on stage of lactation and time since milk ejection in the udder of dairy cows. J. Dairy Sci. 87:2409-2415. https://doi .org/10.3168/jds.S0022-0302(04)73363-9.

Erskine, R. J., B. Norby, L. M. Neuder, and R. S. Thomson. 2019. Decreased milk yield is associated with delayed milk ejection. J. Dairy Sci. 102:6477-6484. https://doi.org/10.3168/jds.2018-16219.

Hamann, J., and G. A. Mein. 1988. Responses of the bovine teat to machine milking: measurement of changes in thickness of the teat apex. J. Dairy Res. 55:331-338. https://doi.org/10.1017/ S0022029900028582.

Isaksson, A., and O. Lind. 1992. Teat reactions in cows associated with machine milking. J. Vet. Med. A Physiol. Pathol. Clin. Med. 39:282-288. https://doi.org/10.1111/j.1439-0442.1992.tb00184.x.

Kaskous, S., and R. M. Bruckmaier. 2011. Best combination of prestimulation and latency period duration before cluster attachment for efficient oxytocin release and milk ejection in cows with low to high udder-filling levels. J. Dairy Res. 78:97-104. https://doi.org/ 10.1017/S0022029910000816.

Knight, C. H., D. Hirst, and R. J. Dewhurst. 1994. Milk accumulation and distribution in the bovine udder during the interval between milkings. J. Dairy Res. 61:167-177. https://doi.org/10 .1017/S0022029900028181.

Mayer, H., R. Bruckmaier, and D. Schams. 1991. Lactational changes in oxytocin release, intramammary pressure and milking characteristics in dairy cows. J. Dairy Res. 58:159-169. https://doi.org/ 10.1017/S0022029900029708.
Mayer, H., D. Schams, and A. Prokopp. 1984. Effects of manual stimulation and delayed milking on secretion of oxytocin and milking characteristics in dairy cows. Milchwissenschaft 39:666-670.

Neuheuser, A. L., A.-C. Schwinn, O. Wellnitz, L. E. Hernández-Castellano, and R. M. Bruckmaier. 2018. Reduced claw vacuum and b-phase during low milk flow does not impact oxytocin release and milking performance. J. Dairy Res. 85:70-77. https://doi.org/10 $.1017 /$ S0022029917000504.

Odorcic, M., U. Blau, J. Löfstrand, and R. M. Bruckmaier. 2020. Short communication: Teat wall diameter and teat tissue thickness in dairy cows are affected by intramammary pressure and by the mechanical forces of machine milking. J. Dairy Sci. 103:884-889. https://doi.org/10.3168/jds.2019-16565.

Pfeilsticker, H. U., R. M. Bruckmaier, and J. W. Blum. 1996. Cisternal milk in the dairy cow during lactation and after preceding teat stimulation. J. Dairy Res. 63:509-515. https://doi.org/10.1017/ S0022029900032040.

Rasmussen, M. D. 1993. Influence of switch level of automatic cluster removers on milking performance and udder health. J. Dairy Res. 60:287-297. https://doi.org/10.1017/S0022029900027631.

Rasmussen, M. D., E. S. Frimer, and E. L. Decker. 1994. Reverse pressure gradients across the teat canal related to machine milking. J. Dairy Sci. 77:984-993. https://doi.org/10.3168/jds.S0022 -0302(94)77034-X.

Stauffer, C., M. Feierabend, and R. M. Bruckmaier. 2020. Different vacuum levels, vacuum reduction during low milk flow, and different cluster detachment levels affect milking performance and teat condition in dairy cows. J. Dairy Sci. 103:9250-9260. https://doi .org/10.3168/jds.2020-18677.

Vetter, A., H. A. Van Dorland, M. Youssef, and R. M. Bruckmaier. 2014. Effects of a latency period between pre-stimulation and teat cup attachment and periodic vacuum reduction on milking characteristics and teat condition in dairy cows. J. Dairy Res. 81:107112. https://doi.org/10.1017/S0022029913000617.

Weiss, D., and R. M. Bruckmaier. 2005. Optimization of individual prestimulation in dairy cows. J. Dairy Sci. 88:137-147. https://doi .org/10.3168/jds.S0022-0302(05)72671-0.

\section{ORCIDS}

Olga Wellnitz @ https://orcid.org/0000-0002-5817-3428

Rupert M. Bruckmaier ๑ https://orcid.org/0000-0002-9374-5890 